\title{
miR-127 contributes to ventilator-induced lung injury
}

\author{
QIAN LI $^{1 *}$, YA-LI GE ${ }^{2 *}$, MIN LI $^{3}$, XIANG-ZHI FANG ${ }^{2}$, YAN-PING YUAN ${ }^{1}$, \\ LEI LIANG $^{4}$ and SHAO-QIANG HUANG ${ }^{1}$
}

\begin{abstract}
${ }^{1}$ Department of Anesthesiology, Obstetrics and Gynecology Hospital, Fudan University, Shanghai 200433; ${ }^{2}$ Department of Anesthesiology, Subei People's Hospital of Jiangsu, Yangzhou, Jiangsu 225001; ${ }^{3}$ Department of Anesthesiology, Affiliated People's Hospital of Jiangsu University, Zhenjiang, Jiangsu 212000; ${ }^{4}$ Department of Colorectal Surgery, Fudan University Shanghai Cancer Center, Shanghai 200032, P.R. China
\end{abstract}

Received June 1, 2016; Accepted April 27, 2017

DOI: $10.3892 / \mathrm{mmr} .2017 .7109$

\begin{abstract}
Although it is essential in critical care medicine, mechanical ventilation often results in ventilator-induced lung injury (VILI). Treating mice with lipopolysaccharide has been reported to upregulate the expression of miR-127, which has been implicated in the modulation of immune responses. However, the putative roles of miR-127 during the development of VILI have yet to be elucidated. The present study demonstrated that challenging mice with mechanical ventilation for $6 \mathrm{~h}$ significantly upregulated the expression of miR-127 in bronchoalveolar lavage fluid, serum and lung tissue samples. Conversely, following the downregulation of miR-127 expression in vivo using an adenovirus delivery system, VILI-associated pathologies, including alterations in the pulmonary wet/dry ratio, pulmonary permeability, lung neutrophil infiltration and levels of pro-inflammatory cytokines, were significantly attenuated. In addition, miR-127 knockdown inhibited the ventilation-induced activation of nuclear factor (NF)- $\mathrm{kB}$ and $\mathrm{p} 38$ mitogen-activated protein kinase (MAPK). These findings suggested that the upregulation of miR-127 expression may contribute to the development of VILI, through the modulation of pulmonary permeability, the induction of histopathological alterations, and the potentiation of inflammatory responses involving NF- $\mathrm{KB}$ and p38 MAPK-associated signaling pathways.
\end{abstract}

\section{Introduction}

Mechanical ventilation is a life-saving intervention for critically ill patients with acute respiratory failure. However, the

Correspondence to: Dr Shao-Qiang Huang, Department of Anesthesiology, Obstetrics and Gynecology Hospital, Fudan University, 220 Handan Road, Shanghai 200433, P.R. China

E-mail: drhuangsq@163.com

*Contributed equally

Key words: miR-127, lung injury, mechanical ventilation, inflammation ventilation procedure has been associated with the development of ventilator-induced lung injury (VILI) (1). The pathogenesis of VILI has been reported to involve excessive, uncontrolled inflammatory responses in the lungs; however, the molecular mechanisms underlying the development of VILI have yet to be elucidated $(2,3)$. Inflammatory responses during the pathogenesis of VILI have been revealed to exacerbate lung damage, including alveolar-capillary barrier injury, and can result in the development of alveolar edema (4). Therefore, the need to elucidate the molecular mechanisms implicated in the progression of VILI is imperative for the development of novel preventive and therapeutic approaches for the treatment of patients with VILI.

MicroRNAs (miRNAs) are a class of small, endogenous, noncoding RNA molecules with a length of 22 nucleotides, that are involved in the post-transcriptional regulation of gene expression, via targeting the 3 ' untranslated regions of target genes (5). miR-127 has been revealed to be highly expressed in embryos and has been implicated in lung development, placenta formation and cellular apoptosis (6). Aberrant miR-127 expression has been associated with an increased risk of prostate, bladder and colon cancer $(7,8)$. Previous studies have identified miRNAs as critical regulators during lung and systemic inflammatory responses $(9,10)$, thus suggesting that miRNAs may be involved in the pathogenesis of VILI, which has a significant inflammatory component (11). Notably, miR-127 has been reported to be upregulated in inflammatory pulmonary disorders, including lung fibrosis and bleomycin or immunocomplex-induced lung injury $(12,13)$. In addition, miR-127 is upregulated in response to lipopolysaccharide-induced stimulation of macrophages (14), thus suggesting that miR-127 may be involved in the modulation of immune responses.

In response to mechanical stress, a series of intracellular signaling cascades are initiated, ultimately leading to the excessive production of pro-inflammatory cytokines, including tumor necrosis factor (TNF)- $\alpha$, interleukin (IL)-1 $\beta$ and IL-6, as well as neutrophil recruitment to the lungs $(15,16)$. The present study aimed to investigate whether mechanical ventilation may alter the expression of miR-127, and whether aberrant miR-127 expression may contribute to the development of VILI. Therefore, a mouse model of VILI was employed to study the involvement of miR-127 in the pathogenesis of VILI. 


\section{Materials and methods}

Animals. A total of 128 C57BL/6 female mice (age, 6 weeks; weight, 20-25 g) were obtained from the Center of Comparative Medicine of Yangzhou University (Yangzhou, China). Animals were housed at $24 \pm 2^{\circ} \mathrm{C}$, under 12 -h light/dark cycles with free access to food and water. The study was approved by the Laboratory Animal Ethics Committee of Yangzhou University Medical Academy. Mice were anesthetized prior to tracheotomy through intraperitoneal administration of carbrital $(40 \mathrm{mg} / \mathrm{kg})$.

Adenoviral plasmids encoding miR-127-specific short hairpin (sh)RNA. Adenoviral plasmids encoding miR-127-specific (UGUGAUCACUGUCUCCAGCCUGCUGAAGCUCAG) and control non-specific (UUGGCAUUGUGCACUACACCC UGCUUUAAUUU) shRNAs were obtained by Thermo Fisher Scientific, Inc. (Waltham, MA, USA). The miR-127-targeting and control plasmids were termed Ad-shmiR-127 and Ad-shNeg, respectively. Adenoviruses were prepared by Thermo Fisher Scientific, Inc. and the viral titer was determined by infecting these adenovirus cultures at a multiplicity of infection of 50. Viral stocks with titers of $10^{11}-10^{12}$ infectious units $/ \mathrm{ml}$ were used in experiments.

Mouse model of VILI. A total of $1.3 \mathrm{ml}$ Ad-shmiR-127 $(\mathrm{n}=18)$ or Ad-shNeg ( $\mathrm{n}=18)$ virus was administered (as viral particles) to each mouse via hydrodynamic injection into the tail vein (17). On day 3 following injection, mice were tracheotomized through the insertion of a blunted 20 -gauge needle into the trachea. Mice were ventilated for $6 \mathrm{~h}$ using a small-animal ventilator (DW3000; Huaibei Zhenghua Biologic Apparatus Facilities Co., Ltd., Huaibei, China), with a high tidal volume of $30 \mathrm{ml} / \mathrm{kg}$ and without positive end expiratory pressure. Mice in the control group were allowed to breathe spontaneously for $6 \mathrm{~h}$. Mice in the VILI group received only mechanical ventilation and no adenovirus infection. Mice were sacrificed following mechanical ventilation, and tissue samples were harvested for further analysis.

Reverse transcription-quantitative polymerase chain reaction (RT-qPCR). RT-qPCR was used to assess the expression levels of miR-127 (forward, 5'-ATGTCACTGTTAACCAGCCTG CT-3' and reverse, 3'-TTA ACTTACGAGGGAGGCAGA TGA-5'), as previously described (18). All reagents, primers and probes were obtained from Invitrogen; Thermo Fisher Scientific, Inc. Total RNA was extracted using TRIzol ${ }^{\circledR}$ reagent and cDNA was synthesized using the PrimeScript ${ }^{\mathrm{TM}}$ RT reagent kit (Takara Biotechnology Co., Ltd., Dalian, China), according to the manufacturer's protocol. A TaqMan ${ }^{\circledR}$ miRNA assay (Applied Biosystems; Thermo Fisher Scientific, Inc.) was used to quantify the expression levels of miR-127, according to the manufacturer's protocol. The following thermocycling conditions were used: Denaturation at $95^{\circ} \mathrm{C}$ for $3 \mathrm{~min}$, followed by 40 cycles of $95^{\circ} \mathrm{C}$ for $12 \mathrm{sec}$ and $62^{\circ} \mathrm{C}$ for $40 \mathrm{sec}$, and then a melting curve program from 62 to $95^{\circ} \mathrm{C}$ (read every $0.2^{\circ} \mathrm{C}$, held for $2 \mathrm{sec}$ ). U6 small nuclear RNA (forward, 5'-AAAGCAAAT CATCGGACGACC-3' and reverse, 3'-GTACAACACATTGTT TCCTCGGA-5') was used as the internal control. Relative gene expression was calculated according to the $2^{-\Delta \Delta C q}$ method (19).
Lung water content and histological evaluation. The upper left lung was weighed, dried in an oven at $80^{\circ} \mathrm{C}$ for $72 \mathrm{~h}$, then weighed again to calculate the pulmonary wet/dry (W/D) ratio. Lung tissues were fixed at room temperature for $24 \mathrm{~h}$ in a $4 \%$ paraformaldehyde-buffered solution, paraffin-embedded and then cut into sections $(3 \mu \mathrm{m})$. At room temperature, paraffin sections were dewaxed twice in xylene for 15 and $20 \mathrm{~min}$, respectively, after drying for $45 \mathrm{~min}$, then treated with a descending ethanol series and washed in tap water for $2 \mathrm{~min}$. Following staining with hematoxylin for $5 \mathrm{~min}$ and washing with tap water, the slides were differentiated in $1 \%$ acid alcohol, blued in $1 \%$ ammonia water, counterstained with eosin for $1 \mathrm{~min}$ and washed with tap water again. They were then dehydrated by a descending ethanol series, cleared twice in xylene for 10 min each and mounted with neutral gum. The sections were examined and photographed by an Olympus CX21 light microscope (magnification, x400; Olympus Corporation, Tokyo, Japan). The degree of lung injury was assessed as previously described by Murakami et al (20). Briefly, the extent of edema, congestion, inflammatory cell infiltration and hemorrhage were graded according to the following 5-point scale: Absent, 0; light, 1; moderate, 2; strong, 3; and intense, 4. The scores for each histopathological feature were summed to obtain a total score for each animal.

Pulmonary microvascular permeability. Ventilation-induced changes in pulmonary microvascular permeability were assessed using a modification of the Evans blue dye extravasation technique, as previously described (21). Briefly, $30 \mathrm{~min}$ prior to the initiation of mechanical ventilation, $1 \%$ Evans blue dye (Beijing Solarbio Science \& Technology Co., Ltd., Beijing, China) dissolved in PBS was injected into the tail vein of mice at a dose of $30 \mathrm{mg} / \mathrm{kg}$. Following ventilation, blood samples were collected via right ventricular puncture and plasma was isolated via centrifugation at $3,000 \mathrm{x} \mathrm{g}$ for $10 \mathrm{~min}$ at $4^{\circ} \mathrm{C}$. Lungs were perfused free of blood by injecting the right ventricle with $10 \mathrm{ml}$ of sterile PBS. The left lung was isolated and homogenized in $0.5 \mathrm{ml}$ of formamide (Sigma-Aldrich; Merck KGaA, Darmstadt, Germany). Lung homogenates were incubated overnight at $60^{\circ} \mathrm{C}$, then centrifuged at $4,000 \mathrm{x}$ g for $30 \mathrm{~min}$ at $4^{\circ} \mathrm{C}$. The optical density of the lung homogenates and diluted plasma samples was measured at 620 and $740 \mathrm{~nm}$ and the permeability index was calculated, as previously described (22).

Total cell and neutrophil counts in bronchoalveolar lavage (BAL) fluid. Following mechanical ventilation for $6 \mathrm{~h}$, BAL fluid samples were obtained via cannulating the trachea with a blunt 20-gauge needle and slowly infusing the lungs with $1 \mathrm{ml}$ of ice-cold PBS, then withdrawing the needle. The procedure was performed three times. Total cell counts in BAL fluid were determined using a hemocytometer. A cytocentrifuged spin preparation (CF-RD; Sakura Finetek Europe B.V., Flemingweg, Netherlands) of the BAL fluid was stained with $10 \%$ Wright-Giemsa for $30 \mathrm{~min}$ at room temperature in order to measure the percentage of neutrophils. The remainder of the BAL fluid was centrifuged at $4,000 \mathrm{x} \mathrm{g}$ for $10 \mathrm{~min}$ at $4^{\circ} \mathrm{C}$ and the cell-free supernatant was stored at $-80^{\circ} \mathrm{C}$.

Pro-inflammatory cytokine and total protein levels in BAL fluid. The cell-free BAL supernatant was thawed, and the levels 
of the pro-inflammatory cytokines TNF- $\alpha$ (cat no. SMTA00B), IL-1 $\beta$ (cat no. SMLB00C) and IL-6 (cat no. D6050) (all from R\&D Systems, Inc., Minneapolis, MN, USA) were determined using murine cytokine-specific Quantikine ${ }^{\circledR}$ ELISA kits, according to the manufacturer's protocol. Total protein concentration was measured using a bicinchoninic acid (BCA) protein assay kit (cat no. P0009; Beyotime Institute of Biotechnology, Haimen, China), according to the manufacturer's protocol.

Pulmonary neutrophil infiltration. Lung myeloperoxidase (MPO) activity was assessed as an index of lung neutrophil infiltration. Briefly, lung tissue $(1 \mathrm{~g})$ was homogenized in $1 \mathrm{M}$ PBS (pH 7.4), freeze-thawed three times in liquid nitrogen, and centrifuged at $12,000 \mathrm{x} \mathrm{g}$ at $4^{\circ} \mathrm{C}$ for $10 \mathrm{~min}$. The supernatants were collected and MPO activity was assessed using a commercially available kit (Nanjing Jiancheng Bioengineering Institute, China), according to the manufacturer's protocol.

Western blot analysis. The harvested lung tissue was weighed, homogenized in protein lysis buffer (cat no. P0013B; Beyotime Institute of Biotechnology), and centrifuged at $12,000 \mathrm{x} \mathrm{g}$ and $4^{\circ} \mathrm{C}$ for $15 \mathrm{~min}$. Total protein concentration in lung tissue homogenates was assessed using a BCA protein assay kit (cat no. P0009; Beyotime Institute of Biotechnology), according to the manufacturer's protocol, using bovine serum albumin as the calibration standard. Equal amounts $(20 \mu \mathrm{l})$ of protein samples were resolved by $10 \%$ SDS-PAGE and transferred onto polyvinylidene difluoride membranes. The membrane was blocked with 5\% non-fat milk in TBST buffer $(10 \mathrm{mM}$ Tris-HCl, $\mathrm{pH} 7.5$, $150 \mathrm{mM} \mathrm{NaCl}$ and $1.2 \%$ Tween-20) at room temperature for $1 \mathrm{~h}$. Membranes were incubated with the following primary antibodies: Anti-inhibitor IкB (cat no. ab32518; 1:300; Abcam, Cambridge, UK), anti-phosphorylated (p)-ІкB (cat no. 2859; 1:500), anti-p-p38 mitogen-activated protein kinase (MAPK; cat no. 4511; 1:500), anti-p-extracellular signal-activated kinase (cat no.14227; 1:500) (all from Cell Signaling Technology, Inc., Danvers, MA, USA) and anti- $\beta$-actin antibody (cat no. AA128; 1:500; Beyotime Institute of Biotechnology) at $4^{\circ} \mathrm{C}$ for $12 \mathrm{~h}$. Subsequently, membranes were incubated at room temperature for $1 \mathrm{~h}$ with the secondary antibody conjugated to horseradish peroxidase (cat no. A0208; 1:200; Beyotime Institute of Biotechnology). Protein bands were visualized using enhanced chemiluminescence with an ECL Western Blotting system (Bio-Rad Laboratories, Inc., Hercules, CA, USA).

Statistical analysis. Data were expressed as the mean \pm standard deviation. Statistical analysis was performed using SPSS software version 19.0 (IBM Corp., Armonk, NY, USA). Significance of the differences between groups was assessed using unpaired Student's t-test for pair-wise comparisons or one-way analysis of variance followed by a post hoc Bonferroni test for multiple comparisons. $\mathrm{P}<0.05$ was considered to indicate a statistically significant difference.

\section{Results}

VILI upregulates miR-127 expression. To investigate the putative roles of miR-127 in the pathogenesis of VILI, miR-127 expression was assessed in BAL fluid isolated from mice that received mechanical ventilation for $6 \mathrm{~h}$. miR-127 expression
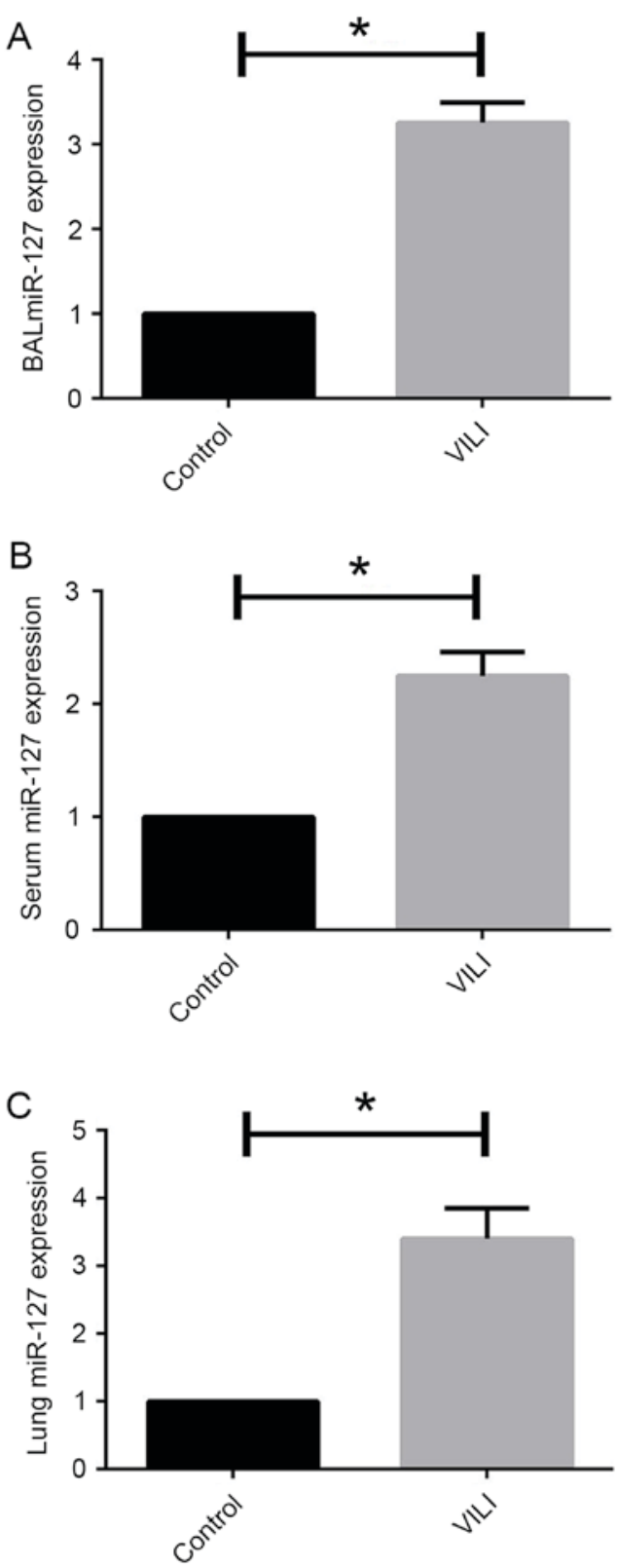

Figure 1. VILI upregulates miR-127 expression. Mice in the VILI group received mechanical ventilation for $6 \mathrm{~h}$. Mice in the control group were allowed to breathe spontaneously. Reverse transcription-quantitative polymerase chain reaction was used to assess miR-127 expression. miR-127 expression levels were significantly upregulated in (A) BAL fluid, (B) peripheral blood and $(C)$ lung tissue samples isolated from the mice. Data are expressed as the mean \pm standard deviation ( $\mathrm{n}=18 /$ group). ${ }^{*} \mathrm{P}<0.05$. VILI, ventilator-induced lung injury; BAL, bronchoalveolar lavage; miR, microRNA.

was significantly increased in ventilated mice compared with mice in the control group, which did not receive mechanical ventilation $(\mathrm{P}<0.05$; Fig. 1A). Similarly, miR-127 expression was upregulated in peripheral blood and lung tissue samples from ventilated mice, compared with mice in the control group $(\mathrm{P}<0.05$; Fig. 1B and $\mathrm{C})$. These results suggested that miR-127 may be implicated in the development of VILI.

Silencing of miR-127 expression following mechanical ventilation via RNA interference. In order to investigate the role of miR-127 in VILI, a mouse model with knockdown miR-127 was 
A

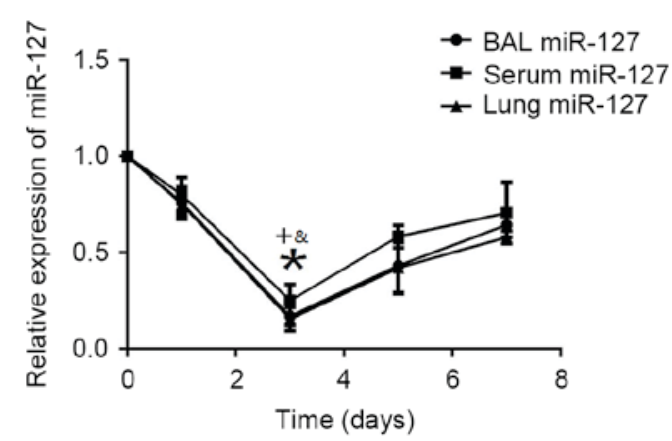

C

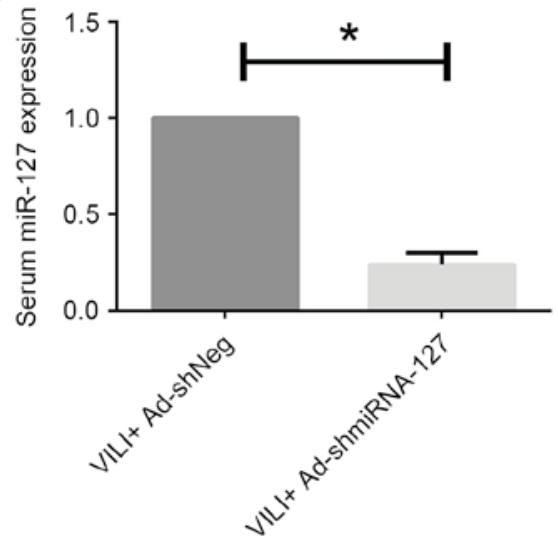

B

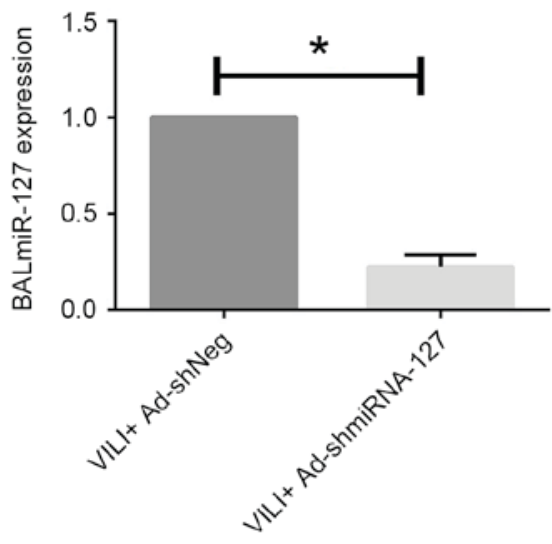

D

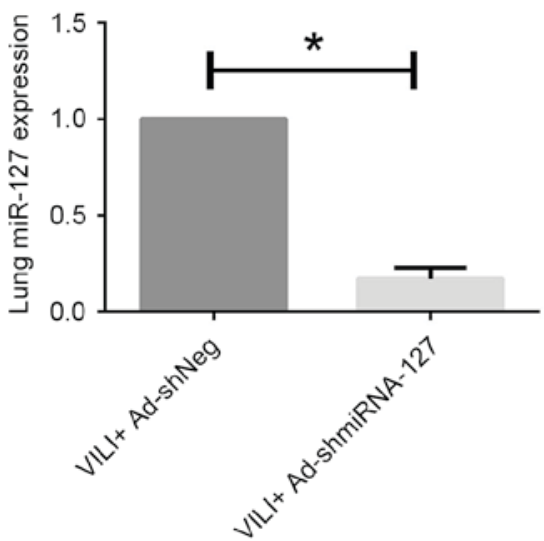

Figure 2. Silencing of miR-127 expression in vivo using RNA interference. (A) miR-127 expression levels were assessed using RT-qPCR in BAL fluid, peripheral blood (serum) and lung tissue samples of mice infected with Ad-shmiR-127 adenovirus for the indicated time points. Data for the Ad-shmiR-127 samples are presented as fold expression relative to the Ad-shNeg control samples. ${ }^{*} \mathrm{P}<0.05$ vs. 1 st day following injection (in BAL fluid, peripheral serum and lung tissue samples); ${ }^{+} \mathrm{P}<0.05$ vs. 5th day following injection (in BAL fluid, peripheral serum and lung tissue samples); ${ }^{\&} \mathrm{P}<0.05$ vs. 7 th day following injection (in BAL fluid, peripheral serum and lung tissue samples). miR-127 expression levels were assessed using RT-qPCR in (B) BAL fluid, (C) peripheral blood and (D) lung tissue samples of mice infected with either Ad-shmiR-127 or Ad-shNeg adenovirus for 3 days and then mechanically-ventilated for 6 h. Data are expressed as the mean \pm standard deviation ( $n=18$ /group). ${ }^{*} \mathrm{P}<0.05$. sh, short hairpin; BAL, bronchoalveolar lavage; RT-qPCR, reverse transcription-quantitative polymerase chain reaction; VILI, ventilator-induced lung injury; miR/miRNA, microRNA.

established via a hydrodynamic injection of Ad-shmiR-127 in the tail vein. A separate group of mice were infected with adenovirus encoding the negative-control, non-targeting shRNA, Ad-shNeg. To confirm that the recombinant adenovirus was successfully transduced in vivo, miR-127 expression in BAL fluid, peripheral blood and lung tissue was assayed on the 1st, 3rd, 5th and 7th day following the Ad-shmiR-127 injection. On day 3 following viral infection, miR-127 expression in BAL fluid, peripheral blood and lung tissue samples was significantly decreased in mice infected with Ad-shmiR-127, when compared with the 1st, 5th and 7 th day following the injection $(\mathrm{P}<0.05$; Fig. $2 \mathrm{~A})$. In addition, miR-127 expression was significantly downregulated in the Ad-shmiR-127 group following mechanical ventilation compared with the Ad-shNeg group ( $\mathrm{P}<0.05$; Fig. 2B-D). These results indicated that the in vivo adenovirus-mediated knockdown of miR-127 was successful in the present study, and was thus used for further experiments to explore the role of miR-127 in the pathogenesis of VILI.

Silencing miR-127 expression attenuates ventilation-induced pulmonary histopathological alterations. Adenovirus-mediated
miR-127 knockdown was used to examine the effects of miR-127 downregulation on the development of VILI. Following mechanical ventilation, tissue samples isolated from mice infected with Ad-shmiR-127 exhibited markedly reduced inflammatory infiltration, vascular congestion, interstitial edema and hemorrhage compared with tissue samples from mice infected with Ad-shNeg (Fig. 3A). In addition, following miR-127 knockdown, mice demonstrated significantly lower lung injury scores compared with non-infected ventilated mice $(\mathrm{P}<0.05$; Fig. 3B), whereas their lung wet/dry ratio was comparable to control mice $(\mathrm{P}<0.05$; Fig. $3 \mathrm{C})$.

Silencing miR-127 expression attenuates ventilation-induced impairment of the alveolar-capillary barrier. Using Evans blue dye perfusion and histological analysis, the permeability of the alveolar-capillary barrier was assessed following mechanical ventilation. The present results revealed that the integrity of the alveolar-capillary barrier was significantly impaired in mechanically-ventilated mice, compared with control mice that received no ventilation ( $\mathrm{P}<0.05$; Fig. 3D). Notably, following miR-127 knockdown, alveolar-capillary 
A
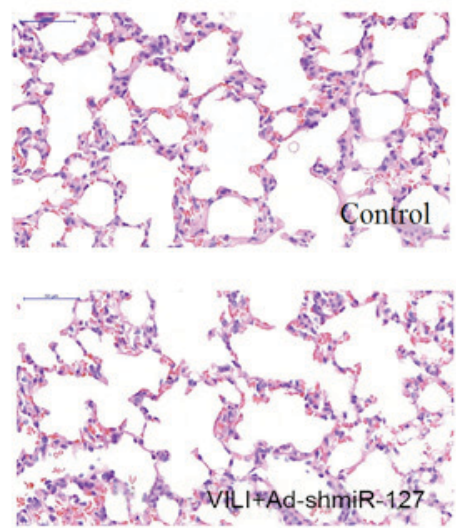

C

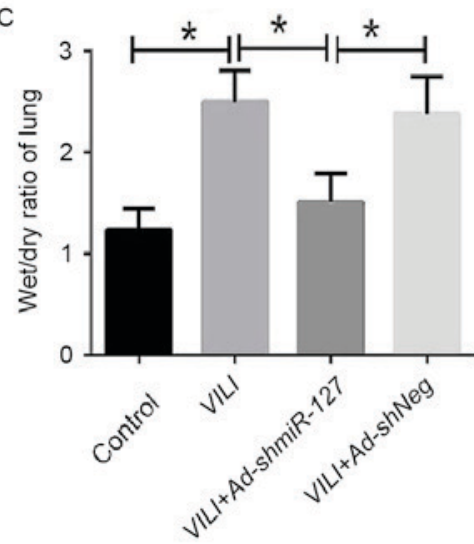

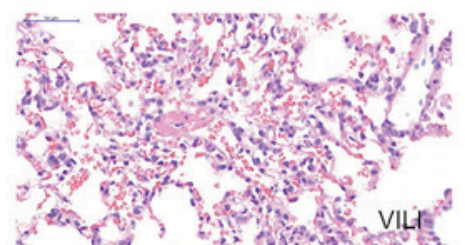

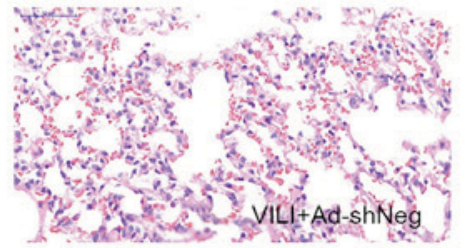

D

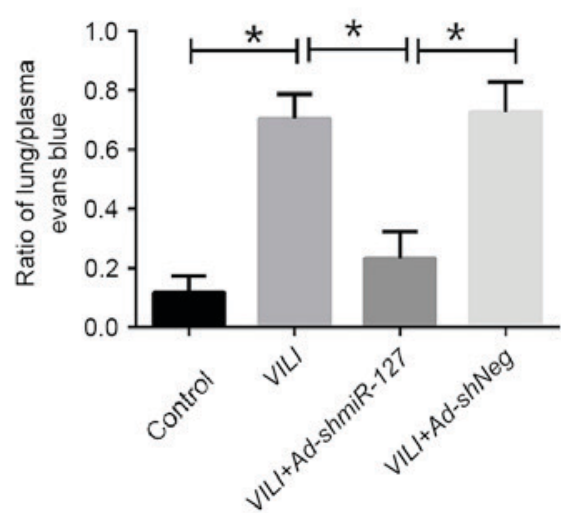

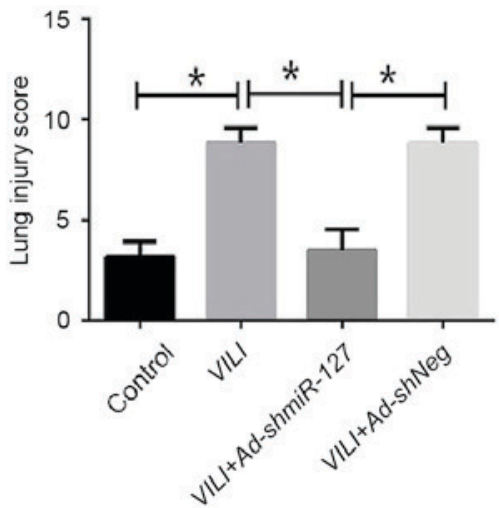

E

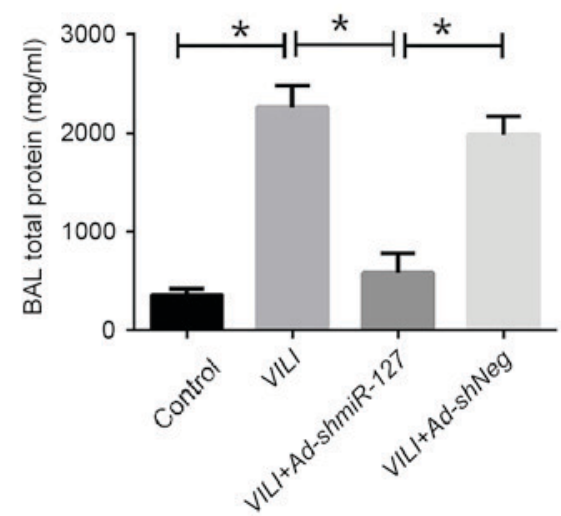

Figure 3. Silencing of miR-127 expression attenuates ventilation-induced pulmonary histopathological alterations. Mice were infected with either Ad-shmiR-127 or Ad-shNeg adenovirus for 3 days and then mechanically-ventilated for $6 \mathrm{~h}$. Control mice were allowed to breathe spontaneously and received no ventilation. (A) Lung tissue samples were isolated, stained with hematoxylin and eosin, and observed under $\mathrm{x} 400$ magnification. The arrows indicate the following: II, inflammatory infiltration; VC, vascular congestion; IE, interstitial edema; H, hemorrhage. miR-127 knockdown significantly attenuated the (B) lung injury score, (C) pulmonary wet/dry ratio, (D) alveolar-capillary barrier permeability as indicated by Evans blue extravasation and (E) total protein concentration in BAL fluid samples. Data are expressed as the mean \pm standard deviation ( $\mathrm{n}=18$ /group). " $\mathrm{P}<0.05$, with comparisons indicated by lines. sh, short hairpin; BAL, bronchoalveolar lavage; VILI, ventilator-induced lung injury; miR, microRNA.

barrier permeability was significantly decreased compared with the Ad-shNeg group $(\mathrm{P}<0.05$; Fig. 3D). Furthermore, following knockdown of miR-127 expression, total protein levels in the BAL fluid of mechanically-ventilated mice were significantly decreased, thus suggesting that the integrity of the alveolar-capillary barrier was preserved $(\mathrm{P}<0.05$; Fig. $3 \mathrm{E})$.

Silencing miR-127 expression attenuates ventilation-induced pulmonary inflammation. Since inflammation has been reported to serve a key role in the pathogenesis of VILI (3), the effects of silencing miR-127 expression on VILI-associated inflammatory responses were investigated. The inflammatory response was evaluated via assessing immune cell numbers and pro-inflammatory cytokine levels in BAL fluid samples from mice following mechanical ventilation. The results demonstrated that, following miR-127 knockdown, total inflammatory cell counts were significantly reduced compared with the VILI+Ad-shNeg group ( $\mathrm{P}<0.05$; Fig. 4A). Similarly, the levels of the pro-inflammatory cytokines TNF- $\alpha$, IL-1 $\beta$ and IL-6 (P<0.05; Fig. 4B), as well as neutrophil counts $(\mathrm{P}<0.05$; Fig. $4 \mathrm{C})$ were significantly decreased in Ad-shmiR-127-infected mice, compared with the Ad-shNeg-infected mice, following mechanical ventilation.
Silencing miR-127 expression prevents ventilation-induced MPO activation. Mechanical ventilation has been reported to enhance pulmonary MPO activity, which reflects the accumulation of polymorphonuclear neutrophils in the lungs (23). The results revealed that following miR-127 expression knockdown, MPO activity was significantly suppressed following mechanical ventilation compared with non-infected ventilated mice (VILI group) and mice in the Ad-shNeg group $(\mathrm{P}<0.05$; Fig. 4D).

Silencing miR-127 expression alters the protein expression of intracellular signaling kinases in VILI. Since miR-127 knockdown was revealed to suppress the ventilation-induced inflammatory response, the molecular mechanisms underlying its effects were investigated. VILI has been reported to activate the pro-inflammatory transcription factor $\mathrm{NF}-\kappa \mathrm{B}$ (14), and this activation depends on the phosphorylation and subsequent degradation of the inhibitor of $\mathrm{NF}-\kappa \mathrm{B}, \mathrm{I} \kappa \mathrm{B}(24) . \mathrm{NF}-\kappa \mathrm{B}$ activation may thus be monitored through the assessment of $\mathrm{I} \kappa \mathrm{B}$ and $\mathrm{p}-\mathrm{I} \kappa \mathrm{B}$ levels $(25,26)$. In the present study, mechanical ventilation was demonstrated to increase $\mathrm{p}-\mathrm{I} \kappa \mathrm{B}$ and decrease IкB pulmonary levels (Fig. 4E). Notably, following miR-127 knockdown, pulmonary levels of $\mathrm{p}-\mathrm{I} \kappa \mathrm{B}$ were downregulated, 

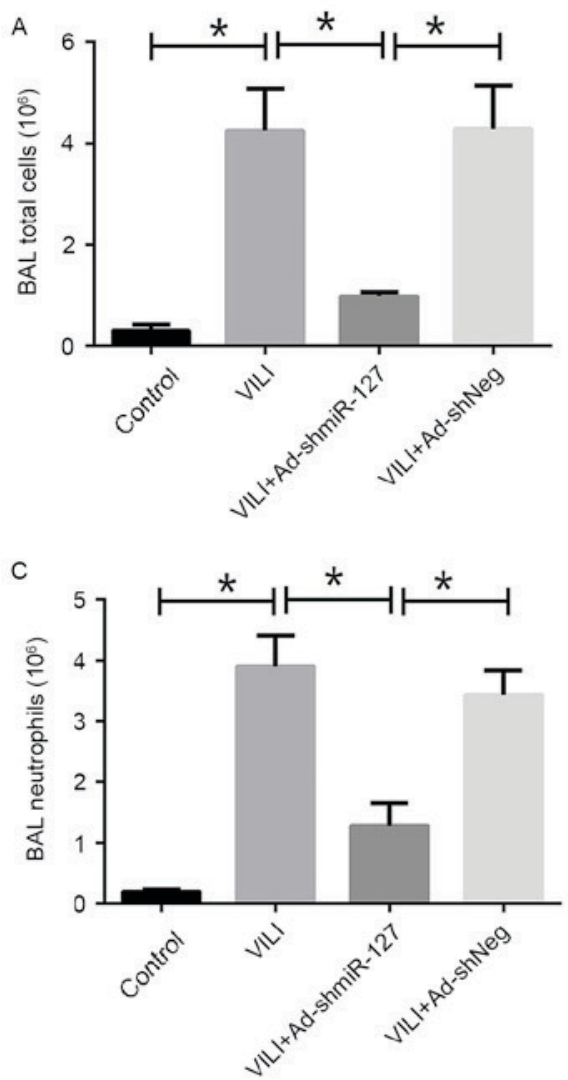

B

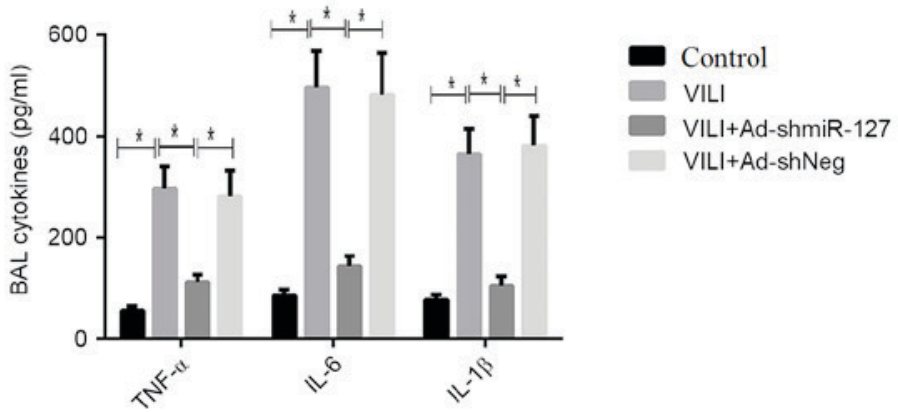

$\mathrm{D}$
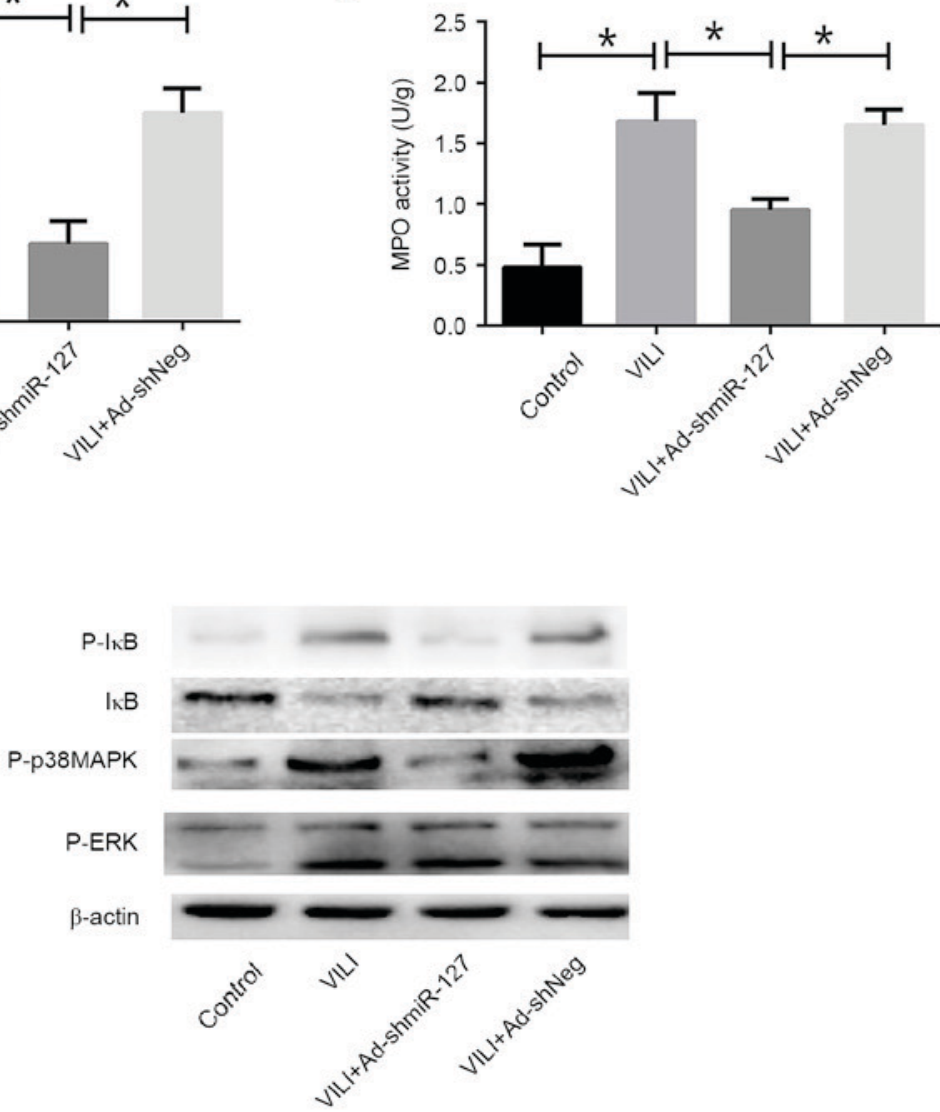

Figure 4. Silencing of miR-127 expression attenuates ventilation-induced pulmonary inflammation. Mice were infected with either Ad-shmiR-127or Ad-shNeg adenovirus for 3 days and then mechanically-ventilated for $6 \mathrm{~h}$. Control mice were allowed to breathe spontaneously and received no ventilation. (A) Total inflammatory cell counts in BAL fluid samples. (B) Pro-inflammatory cytokine levels in BAL fluid samples were assessed using ELISA. (C) Neutrophil counts in BAL fluid samples. (D) MPO activity was assessed as an index of pulmonary neutrophil infiltration in lung tissue samples. (E) Western blot analysis was used to assess the protein expression levels of IкB, p-IкB, p-p38 MAPK and p-ERK in lung tissue samples. $\beta$-actin was used as a loading control. Data are expressed as the mean \pm standard deviation ( $\mathrm{n}=18$ /group). " $\mathrm{P}<0.05$, with comparisons indicated by lines. sh, short hairpin; BAL, bronchoalveolar lavage; MPO, myeloperoxidase; IкB, inhibitor of $\kappa \mathrm{B}$; p-, phosphorylated; MAPK, mitogen-activated protein kinase; ERK, extracellular signal-regulated kinase; VILI, ventilator-induced lung injury; miR, microRNA; TNF, tumor necrosis factor; IL, interleukin.

whereas levels of $\mathrm{I} \kappa \mathrm{B}$ were upregulated in ventilated mice (Fig. 4E), suggesting that NF- $\mathrm{KB}$ activation may be suppressed when miR-127 expression is silenced. In addition, mechanical ventilation enhanced 38 MAPK phosphorylation in lung tissue samples, and following miR-127 knockdown, p-p38 levels appeared to be downregulated (Fig. 4E). ERK phosphorylation was also potentiated as a result of mechanical ventilation, however, miR-127 knockdown had no effect on p-ERK pulmonary levels (Fig. 4E). These findings suggested that ventilation-induced miR-127 upregulation may contribute to the pathophysiology of VILI through the activation of the NF-kB- and p38 MAPK signaling pathways.

\section{Discussion}

The results of the present study suggested that miR-127 may contribute to the development of VILI. Mice that received mechanical ventilation exhibited significantly upregulated 
miR-127 expression in BAL fluid, peripheral blood and lung tissue samples. Following knockdown of miR-127 expression, ventilation-induced lung damage was significantly attenuated, and the lung wet/dry ratio and pulmonary inflammatory cell infiltration were also decreased. In addition, the levels of total protein, pro-inflammatory cytokines and the pro-inflammatory factors $\mathrm{NF}-\kappa \mathrm{B}$ and p38 MAPK in BAL fluid samples, indicative of the presence of VILI, were also downregulated following the silencing of miR-127 expression.

In the present study, miR-127 expression in mice was silenced prior to the induction of mechanical ventilation, through the in vivo delivery of recombinant adenovirus encoding a miR-127-targeting shRNA, as previously described (27-29). Infection and gene silencing was successful, as indicated by the significant decrease in miR-127 levels in BAL fluid, peripheral blood and lung tissue samples compared with mice infected with negative-control shRNA, prior to and following mechanical ventilation.

The present results are in accordance with previous studies that have identified miRNAs as key regulators of numerous biological processes, including the activation of the innate immune response (30-33). Ying et al (14) demonstrated that lipopolysaccharide-induced stimulation of RAW 264.7 murine macrophages in vitro upregulated the expression of miR-127, which was suggested to function as a molecular switch during macrophage development. In the present study, miR-127 knockdown was revealed to effectively attenuate VILI, which is characterized by pulmonary edema, neutrophilic inflammatory responses and the release of inflammatory mediators (15). The present results demonstrated that following miR-127 knockdown, pulmonary edema was attenuated and the lung wet/ dry ratio, indicative of lung water contents, returned to physiological levels. In addition, MPO activity was suppressed, thus suggesting that reduced neutrophil sequestration occurred in the lung, since MPO is a major constituent of neutrophil cytoplasmic granules (23). Downregulation of miR-127 expression was also revealed to attenuate the ventilation-induced impairment in alveolar-capillary barrier permeability, and reduce the total protein levels in the BAL fluid.

Pro-inflammatory cytokines which appear in the early stages of the inflammatory response have been reported to serve a critical role in the pathogenesis of VILI (34). Elevated TNF- $\alpha$ levels have been reported in BAL fluid samples isolated from patients with VILI or acute respiratory distress syndrome $(35,36)$. IL- $1 \beta$ has also been identified as a critical component of VILI pathophysiology (37), as it has been reported to inhibit fluid transport across the distal lung epithelium, thus inducing surfactant abnormalities and increasing the protein permeability of the alveolar-capillary barrier. IL-6 has also been suggested as a marker of VILI (38). TNF- $\alpha$, IL- $1 \beta$ and IL- 6 have been reported to initiate and amplify the inflammatory cascade directly causing inflammatory injury, whereas they can also recruit neutrophils into the lung leading to increased pulmonary MPO activity (3). In the present study, following knockdown of miR-127 expression, ventilation-induced increases in TNF- $\alpha$, IL-1 $\beta$ and IL-6 levels were significantly attenuated. These findings suggested that miR-127 may contribute to the pathogenesis of VILI, via stimulating the production of inflammatory cytokines.
$\mathrm{NF}-\kappa \mathrm{B}$ has been identified as a critical regulator of pro-inflammatory cytokine expression; activation of the $\mathrm{NF}-\kappa \mathrm{B}, \mathrm{p} 38$ MAPK and ERK signaling pathways has been suggested to initiate lung inflammatory responses, triggered by excessive mechanical stress during ventilation $(15,39,40)$. Under physiological conditions, $N F-\kappa B$ is present in the cytoplasm in an inactive form bound to $\mathrm{I} \kappa \mathrm{B}$. In response to

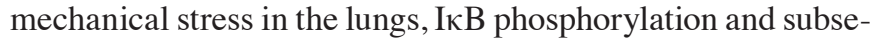
quent degradation is initiated, leading to the release of $\mathrm{NF}-\kappa \mathrm{B}$, which then translocates to the nucleus and activates expression of pro-inflammatory genes, including TNF- $\alpha$, IL-1 $\beta$ and IL-6 (3). Therefore, the present study investigated the effects of miR-127 expression manipulations on the activation of NF- $\mathrm{B}, \mathrm{p} 38$ MAPK and ERK pathways, which are implicated in the regulation of cytokine production. The present results demonstrated that silencing miR-127 expression appeared to inhibit the ventilation-induced activation of $\mathrm{NF}-\kappa \mathrm{B}$ and p38 MAPK; however, activation of ERK was not affected. These findings suggested that miR-127 may contribute to the development of VILI through the activation of NF- $\mathrm{BB}$ and $\mathrm{p} 38$ MAPK signaling, thus triggering the expression of inflammatory mediators in the lungs.

While the present study demonstrated that miR-127 positively regulated the inflammatory response during mechanical ventilation, previous studies involving different lung injury models have suggested that miR-127 negatively regulated inflammatory responses during the development of lung injury $(12,41)$. The different lung injury models used in these studies may underlie the apparent discrepancy. In addition, the assessment of miR-127 expression at different time points following the induction of lung injury may have affected the results. Further studies are required to investigate whether miR-127 may differentially regulate inflammatory pathways in different models, or whether it may exert varying effects at different time points during the inflammatory process.

In conclusion, the present study suggested that miR-127 may contribute to mechanical ventilation-induced inflammatory responses in the lungs, through the activation of $\mathrm{NF}_{-} \kappa \mathrm{B}$ and p38 MAPK signaling pathways, leading to alveolar-capillary barrier dysregulation during the pathogenesis of VILI. The present findings suggested that miR-127 may have potential as a novel therapeutic target for the development of strategies to attenuate VILI in patients receiving mechanical ventilation.

\section{Acknowledgements}

The present study was funded by the National Natural Science Fund (grant no. 81401626).

\section{References}

1. Vaporidi K, Vergadi E, Kaniaris E, Hatziapostolou M, Lagoudaki E, Georgopoulos D, Zapol WM, Bloch KD and Iliopoulos D: Pulmonary microRNA profiling in a mouse model of ventilator-induced lung injury. Am J of Physiol Lung Cell Mol Physiol 303: L199-L207, 2012.

2. Frank JA and Matthay MA: Science review: Mechanisms of ventilator-induced injury. Crit Care 7: 233-241, 2002.

3. Ko YA, Yang MC, Huang HT, Hsu CM and Chen LW: NF-кB activation in myeloid cells mediates ventilator-induced lung injury. Respir Res 14: 69, 2013. 
4. Aslami H, Heinen A, Roelofs JJ, Zuurbier CJ, Schultz MJ and Juffermans NP: Suspended animation inducer hydrogen sulfide is protective in an in vivo model of ventilator-induced lung injury. Intensive Care Med 36: 1946-1952, 2010.

5. Schickel R, Boyerinas B, Park SM and Peter ME: MicroRNAs: Key players in the immune system, differentiation, tumorigenesis and cell death. Oncogene 27: 5959-5974, 2008.

6. Bhaskaran M, Wang Y, Zhang H, Weng T, Baviskar P, Guo Y, Gou D and Liu L: MicroRNA-127 modulates fetal lung development. Physiol Genomics 37: 268-278, 2009.

7. Song G and Wang L: Transcriptional mechanism for the paired miR-433 and miR-127 genes by nuclear receptors SHP and ERRgamma. Nucleic Acids Res 36: 5727-5735, 2008.

8. Saito Y, Liang G, Egger G, Friedman JM, Chuang JC, Coetzee GA and Jones PA: Specific activation of microRNA-127 with downregulation of the proto-oncogene BCL6 by chromatin-modifying drugs in human cancer cells. Cancer Cell 9: 435-443, 2006.

9. Ebrahimi A and Sadroddiny E: MicroRNAs in lung diseases: Recent findings and their pathophysiological implications. Pulm Pharmacol Ther 34: 55-63, 2015.

10. Marques-Rocha JL, Samblas M, Milagro FI, Bressan J, Martínez JA and Marti A: Noncoding RNAs, cytokines, and inflammation-related diseases. FASEB J 29: 3595-3611, 2015.

11. Wu J, Yan Z, Schwartz DE, Yu J, Malik AB and Hu G: Activation of NLRP3 inflammasome in alveolar macrophages contributes to mechanical stretch-induced lung inflammation and injury. J Immunol 190: 3590-3599, 2013.

12. Milosevic J, Pandit K, Magister M, Rabinovich E, Ellwanger DC, Yu G, Vuga LJ, Weksler B, Benos PV, Gibson KF, et al: Profibrotic role of miR-154 in pulmonary fibrosis. Am J Respir Cell Mol Biol 47: 879-887, 2012.

13. Xie T, Liang J, Liu N, Wang Q, Li Y, Noble PW and Jiang D: MicroRNA-127 inhibits lung inflammation by targeting IgG Fc $\gamma$ receptor I. J Immunol 188: 2437-2444, 2012.

14. Ying H, Kang Y, Zhang H, Zhao D, Xia J, Lu Z, Wang H, Xu F and Shi L: MiR-127 modulates macrophage polarization and promotes lung inflammation and injury by activating the JNK pathway. J Immunol 194: 1239-1251, 2015.

15. Shu YS, Tao W, Miao QB, Zhu YB and Yang YF: Improvement of ventilation-induced lung injury in a rodent model by inhibition of inhibitory $\kappa$ B kinase. J Trauma Acute Care Surg 76: 1417-1424, 2014.

16. Uhlig U and Uhlig S: Ventilation-induced lung injury. Compr Physiol 1: 635-661,2011.

17. Zeng C, Chen Q, Zhang K, Chen Q, Song S and Fang X: Hepatic hepcidin protects against polymicrobial sepsis in mice by regulating host iron status. Anesthesiology 122: 374-386, 2015.

18. Guo Z, Gu Y, Wang C, Zhang J, Shan S, Gu X, Wang K, Han Y and Ren T: Enforced expression of miR-125b attenuates LPS-induced acute lung injury. Immunol Lett 162: 18-26, 2014.

19. Livak KJ and Schmittgen TD: Analysis of relative gene expression data using real-time quantitative PCR and the 2(-Delta Delta C(T)) method. Methods 25: 402-408, 2001.

20. Murakami K, McGuire R, Cox RA, Jodoin JM, Bjertnaes LJ, Katahira J, Traber LD, Schmalstieg FC, Hawkins HK, Herndon DN and Traber DL: Heparin nebulization attenuates acute lung injury in sepsis following smoke inhalation in sheep. Shock 18: 236-241, 2002

21. Colletti LM, Kunkel SL, Walz A, Burdick MD, Kunkel RG, Wilke CA and Strieter RM: Chemokine expression during hepatic ischemia/reperfusion-induced lung injury in the rat. The role of epithelial neutrophil activating protein. J Clin Invest 95: 134-141, 1995.

22. Belperio JA, Keane MP, Burdick MD, Londhe V, Xue YY, Li K, Phillips RJ and Strieter RM: Critical role for CXCR2 and CXCR2 ligands during the pathogenesis of ventilator-induced lung injury. J Clin Invest 110: 1703-1716, 2002.

23. Luan ZG, Naranpurev M and Ma XC: Treatment of low molecular weight heparin inhibits systemic inflammation and prevents endotoxin-induced acute lung injury in rats. Inflammation 37 : 924-932, 2014

24. Shih RH, Wang CY and Yang CM: NF-kappaB signaling pathways in neurological inflammation: A mini review. Front Mol Neurosci 8: 77, 2015.
25. Han HJ, Li M, Son JK, Seo CS, Song SW and Bae HB: Sauchinone, a lignan from Saururus chinensis, attenuates neutrophil pro-inflammatory activity and acute lung injury. Int Immunopharmacol 17: 471-477, 2013.

26. Zhang SY, Xu LT, Li AX and Wang SM: Effects of ergosterol, isolated from Scleroderma polyrhizum Pers., on lipopolysaccharide-induced inflammatory responses in acute lung injury. Inflammation 38: 1979-1985, 2015

27. Lewis DL, Hagstrom JE, Loomis AG, Wolff JA and Herweijer H: Efficient delivery of siRNA for inhibition of gene expression in postnatal mice. Nat Genet 32: 107-108, 2002

28. Song E, Lee SK, Wang J, Ince N, Ouyang N, Min J, Chen J, Shankar P and Lieberman J: RNA interference targeting Fas protects mice from fulminant hepatitis. Nat Med 9: 347-351, 2003.

29. Wang X, Han L, Zhang A, Wang G, Jia Z, Yang Y, Yue X, $\mathrm{Pu}$ P, Shen C and Kang C: Adenovirus-mediated shRNAs for co-repression of miR-221 and miR-222 expression and function in glioblastoma cells. Oncol Rep 25: 97-105, 2011.

30. Worm J, Stenvang J, Petri A, Frederiksen KS, Obad S, Elmén J, Hedtjärn M, Straarup EM, Hansen JB and Kauppinen S: Silencing of microRNA-155 in mice during acute inflammatory response leads to derepression of c/ebp Beta and down-regulation of G-CSF. Nucleic Acids Res 37: 5784-5792, 2009.

31. Dai R and Ahmed SA: MicroRNA, a new paradigm for understanding immunoregulation, inflammation, and autoimmune diseases. Transl Res 157: 163-179, 2011.

32. Nahid MA, Pauley KM, Satoh M and Chan EK: miR-146a is critical for endotoxin-induced tolerance: Implication in innate immunity. J Biol Chem 284: 34590-34599, 2009.

33. Liu G, Friggeri A, Yang Y, Park YJ, Tsuruta Y and Abraham E: miR-147, a microRNA that is induced upon Toll-like receptor stimulation, regulates murine macrophage inflammatory responses. Proc Nati Acad Sci 106: 15819-15824, 2009.

34. Iwaki M, Ito S, Morioka M, Iwata S, Numaguchi Y, Ishii M, Kondo M, Kume H, Naruse K, Sokabe M and Hasegawa Y: Mechanical stretch enhances IL-8 production in pulmonary microvascular endothelial cells. Biochem Biophys Res Commun 389: 531-536, 2009

35. Rajendrasozhan S, Hwang JW, Yao H, Kishore N and Rahman I: Anti-inflammatory effect of a selective IkabbaB kinase-beta inhibitor in rat lung in response to LPS and cigarette smoke. Pulm Pharmacol Ther 23: 172-181, 2010.

36. Halbertsma FJ, Vaneker M, Scheffer GJ and van der Hoeven JG: Cytokines and biotrauma in ventilator-induced lung injury: A critical review of the literature. Neth J Med 63: 382-392, 2005.

37. Meduri GU, Kohler G, Headley S, Tolley E, Stentz F and Postlethwaite A: Inflammatory cytokines in the BAL of patients with ARDS: Persistent elevation over time predicts poor outcome. Chest 108: 1303-1314, 1995.

38. Nguyen DP, Li J and Tewari AK: Inflammation and prostate cancer: The role of interleukin 6 (IL-6). BJU Int 113: 986-992, 2014.

39. Kim SH, Li M, Pyeon TH, So KY and Kwak SH: The volatile anesthetic sevoflurane attenuates ventilator-induced lung injury through inhibition of ERK1/2 and Akt signal transduction. Korean J Anesthesiol 68: 62-69, 2015.

40. Le A, Damico R, Damarla M, Boueiz A, Pae HH, Skirball J, Hasan E, Peng X, Chesley A, Crow MT, et al: Alveolar cell apoptosis is dependent on p38 MAP kinase-mediated activation of xanthine oxidoreductase in ventilator-induced lung injury. J Appl Physiol (1985) 105: 1282-1290, 2008.

41. Xie T, Liang J, Guo R, Liu N, Noble PW and Jiang D: Comprehensive microRNA analysis in bleomycin-induced pulmonary fibrosis identifies multiple sites of molecular regulation. Physio Genomics 43: 479-487, 2011. 